\title{
A new species of genus Rhinotorus Förster (Ichneumonidae, Ctenopelmatinae) parasitizing Pristiphora erichsonii (Hymenoptera, Tenthredinidae) and a key to Eastern Palaearctic species
}

\author{
Tao Li', Shu-Ping Sun', Mao-Ling Sheng' \\ I General Station of Forest and Grassland Pest Management, National Forestry and Grassland Administration, \\ 58 Huanghe North Street, Shenyang 110034, China \\ Corresponding author: Mao-Ling Sheng (shengmaoling@163.com) \\ Academic editor: Gavin Broad | Received 17 April 2020 | Accepted 15 May 2020 | Published 29 June 2020 \\ http://zoobank.org/2A131A72-D5A2-436C-BFEC-764ED43807CB \\ Citation: Li T, Sun S-P, Sheng M-L (2020) A new species of genus Rhinotorus Förster (Ichneumonidae, Ctenopelmatinae) \\ parasitizing Pristiphora erichsonii (Hymenoptera, Tenthredinidae) and a key to Eastern Palaearctic species. Journal of \\ Hymenoptera Research 77: 203-211. https://doi.org/10.3897/jhr.77.53323
}

\begin{abstract}
A new species of Ctenopelmatinae, Rhinotorus nigrus Sheng, Li \& Sun, sp. nov. reared from cocoons of Pristiphora erichsonii (Hartig) in Jilin Province, China, is described and illustrated. A key to Eastern Palaearctic species of Rhinotorus is provided.
\end{abstract}

\section{Keywords}

Key, new species, Rhinotorus, Mesoleiini, taxonomy

\section{Introduction}

The larch sawfly, Pristiphora erichsonii (Hartig) (Hymenoptera, Tenthredinidae), has been a significant pest of Larix spp. in China and other countries (Xiao 1992; Zhou et al. 1995). It is distributed in the Palaearctic and Nearctic regions (Coppel and Leius 1955; Wong 1974; Richmond et al. 1975; Taeger et al. 2018). Parasitoids of this sawfly include Diptera and Hymenoptera (Muldrew 1967; Zinnert 1969; Pschorn-Walcher

Copyright Tao Li et al. This is an open access article distributed under the terms of the Creative Commons Attribution License (CC BY 4.0), which permits unrestricted use, distribution, and reproduction in any medium, provided the original author and source are credited 
and Zinnert 1971; Drooz 1975; Richmond et al. 1975; Drooz and Thompson 1986). The parasitism rates of Olesicampe nematorum (Tschek) for P. erichsonii about 61\% to $87 \%$ (Muldrew 1967), and the parasitism rate of Olesicampe benefactor Hinz for $P$. erichsonii reached over 90\% in Minnesota (Kulman et al. 1974). In China, there are about 16 species of parasitoids of this sawfly (Sheng and Chen 2001; Li et al. 2014; Yang et al. 2015). The parasitism rates of parasitoids range from $15.9 \%$ to $31.5 \%$ (Li et al. 2014). Parasitoids are playing an important role in terminating larch sawfly outbreaks. In the present research a new parasitoid of Pristiphora erichsonii (Hartig), belonging to the genus Rhinotorus Förster, 1869, was found.

Rhinotorus Förster (Hymenoptera, Ichneumonidae, Ctenopelmatinae) comprises 15 species (Reshchikov 2016; Yu et al. 2016), of which three are from the Eastern Palaearctic Region (also found in the Western Palaearctic) (Meyer 1936; Townes et al. 1965; Reshchikov 2016), 14 from the Western Palaearctic (Reshchikov 2016), and one from the Nearctic Region (Yu et al. 2016).

The species of Rhinotorus Förster were revised by Reshchikov (2016). Prior to the present study the genus has not been recorded in China, nor from the Oriental Region.

The diagnostic characters of Rhinotorus were described by Townes (1970) and expanded upon by Reshchikov (2016).

Nineteen host species of Rhinotorus from ten genera of Tenthredinidae have been recorded, 17 of them belong to subfamily Nematinae (Yu et al., 2016). In the present research parasitism of the genus Rhinotorus Förster, 1869 Pristiphora erichsonii (Hartig) is recorded for the first time.

\section{Material and methods}

\section{Institutional abbreviations}

GSFGPM General Station of Forest and Grassland Pest Management, National Forestry and Grassland Administration, P. R. China;

NHMUK Natural History Museum, London, United Kingdom;

ZISP Zoological Institute of the Russian Academy of Sciences, St. Petersburg, Russia.

\section{Specimen collection and rearing}

Cocoons of sawflies were collected under naturally infested trees in Mt. Maoer, belonging to the branch of Mt. Changbai $\left(42^{\circ} 50^{\prime} \mathrm{N}, 129^{\circ} 28^{\prime} \mathrm{E}\right.$, elevation 375 to $400 \mathrm{~m}$ ), Jilin Province. The forest stand is composed of mixed deciduous angiosperms mainly Quercus mongolica Fischer ex Ledebour and shrubs, with evergreen conifers - Pinus koraiensis Siebold et Zuccarini, P. tabuliformis Carr., and with deciduous conifers - Larix gmelinii (Rupr.) Kuzen., L. kaempferi (Lamb.) Carr., L. principis-rupprechtii Mayr. The detail methods according to Li et al. (2014). 
Images were taken using a Leica M205A stereo microscope with LAS Montage MultiFocus. Morphological terminology is mostly based on Broad et al. (2018). Type specimens are deposited in the Insect Museum, GSFGPM.

\section{Taxonomy}

\section{Rhinotorus Förster, 1869}

Rhinotorus Förster, 1869: 211. Type-species: Spudaea longicornis Schmiedeknecht.

\section{Key to the Eastern Palaearctic species of Rhinotorus}

1 Third metasomal tergite without impression, granulate and impunctate. Coxae yellowish red. Hind tibia black basally and apically and whitish centrally. All tergites black. - Transpalaearctic species, in East: Yakutsk, Kamchatka (Meyer 1936; Townes et al. 1965; Reshchikov 2016) ................... Rh. umbrarum (Holmgren)

- Third metasomal tergite with distinct transverse impression, distinctly punctate. Coxae black. Hind tibia black in apical 0.3 or more with base usually yellowish brownish. Tergites black or some of them reddish

2 Median longitudinal carinae of propodeum (Fig. 7) from anterior margin to posterior transverse carina parallel; area petiolaris with strong median longitudinal carina. Antennal flagellomeres (Fig. 1) and hind femur (Fig. 1) black. - Eastern Palaearctic part of China .......................... Rh. nigrus Sheng, Li \& Sun, sp. nov.

- Median longitudinal carinae of propodeum from anterior margin to posterior transverse carina evidently convergent or divergent posteriorly; area petiolaris without distinct median longitudinal carina. Antennal flagellomeres brown. Hind femur brownish red

3 Median longitudinal carinae of propodeum from anterior margin to posterior transverse carina convergent posteriorly. Scutellum black. Metasomal tergites almost entirely black. - Transpalaearctic species, in East: Yakutsk (Reshchikov 2016)

Rh. compactor (Thunberg)

- Median longitudinal carinae of propodeum from anterior margin to posterior transverse carina divergent posteriorly. Scutellum yellow. Metasomal tergites 2 to 4 reddish brown. - Transpalaearctic species, in East: Kamchatka (Reshchikov 2016)

Rh. leucostomus (Gravenhorst)

\section{Rhinotorus nigrus Sheng, Li \& Sun, sp. nov. \\ http://zoobank.org/CF23EC1D-BA28-4317-BD9D-5CFBAD9BA84A \\ Figures 1-9}

Etymology. The specific name is derived from the entirely black mesosoma and metasoma. 

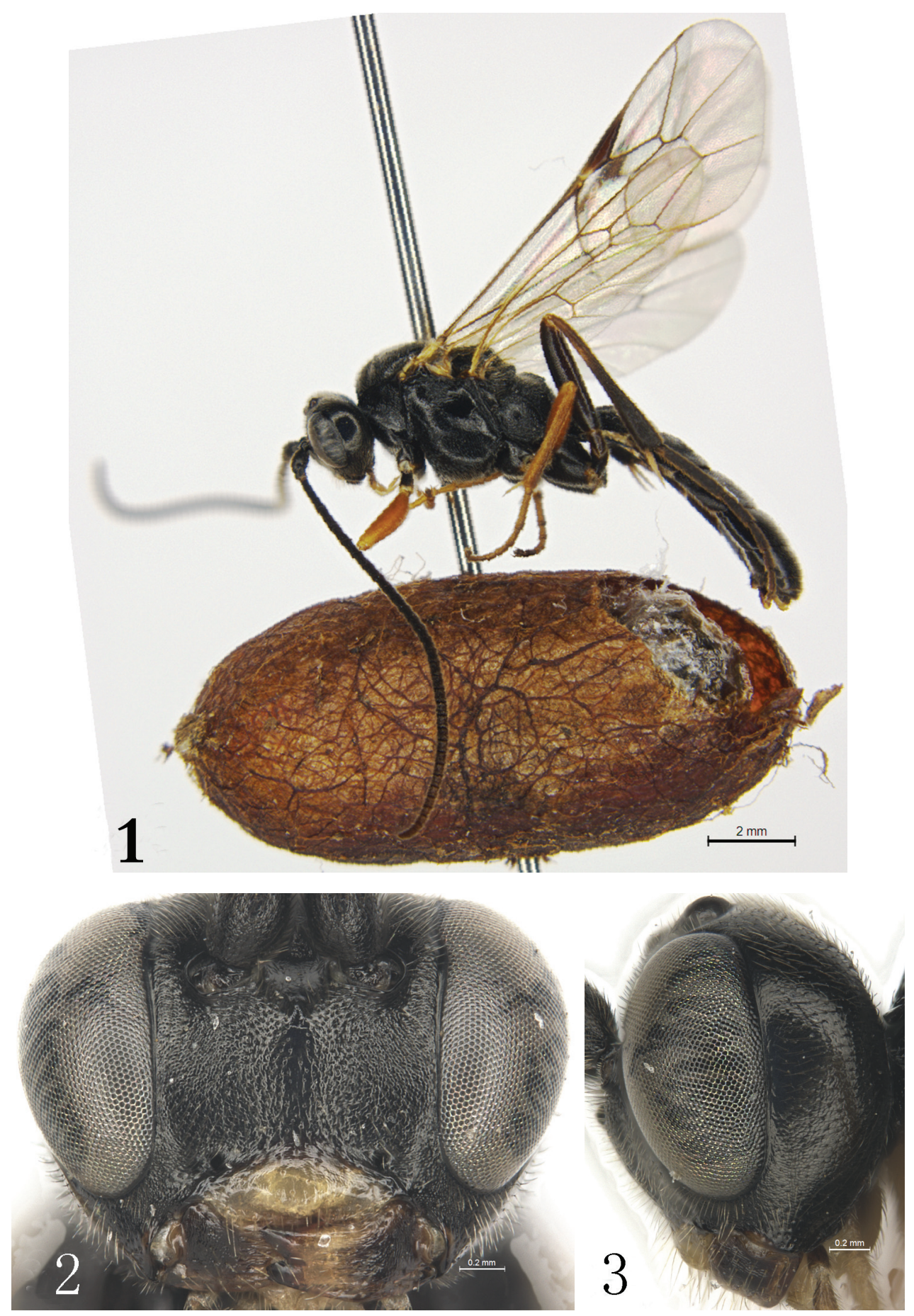

Figures I-9. Rhinotorus nigrus Sheng, Li \& Sun, sp. nov. Holotype, female I habitus and host's cocoon, lateral view $\mathbf{2}$ head, anterior view $\mathbf{3}$ head, lateral view $\mathbf{4}$ head, dorsal view $\mathbf{5}$ head, dorsoanterior view $\mathbf{6}$ mesosoma, lateral view $\mathbf{7}$ propodeum $\mathbf{8}$ metasoma, dorsal view $\mathbf{9}$ apical portion of metasoma, lateral view. 

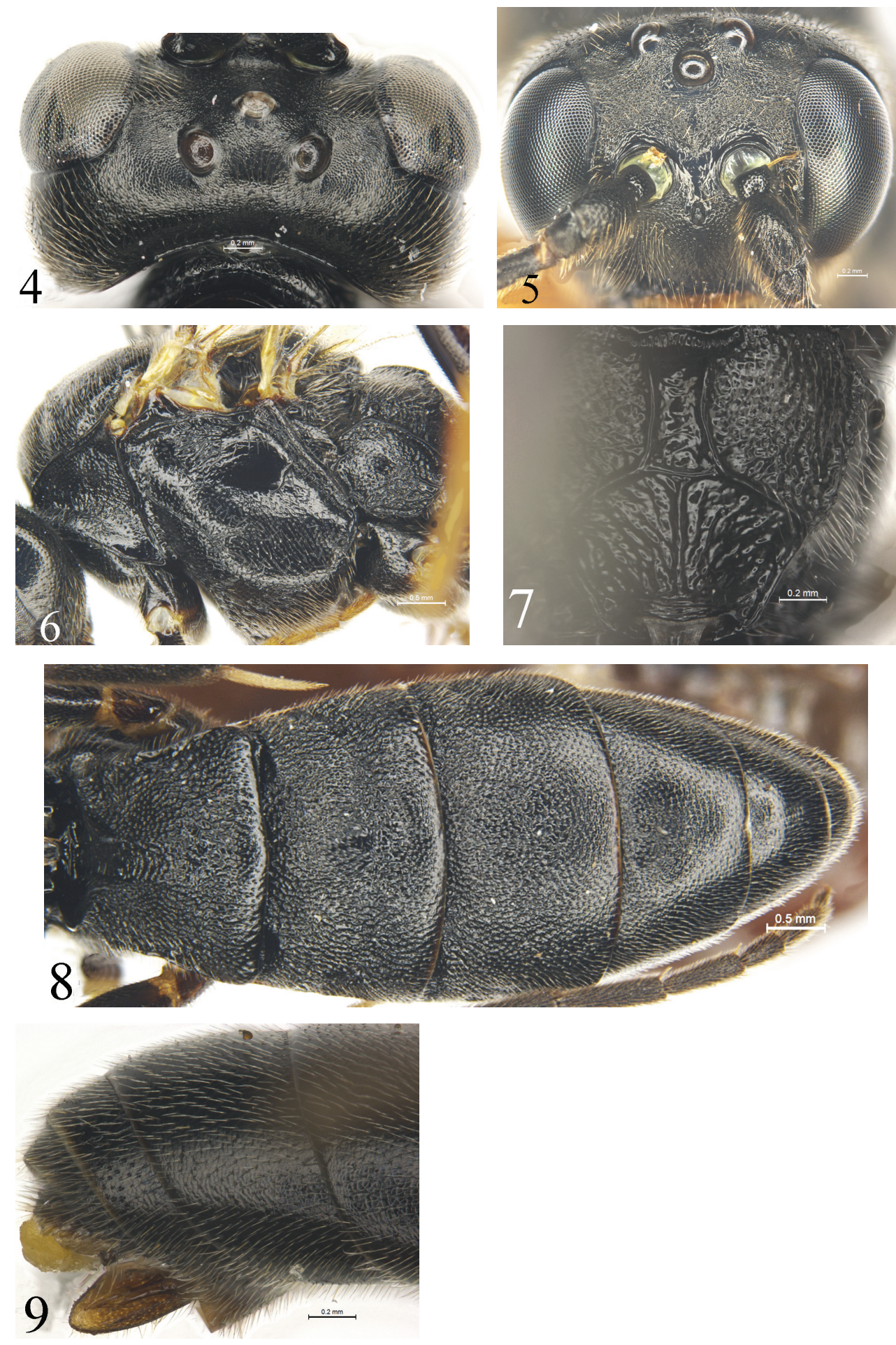

Figures I-9. Continued. 
Material examined. Holotype, female, reared from cocoon of Pristiphora erichsonii (Hartig) in Mt. Maoer, Yanji, Jilin Province, China by Tao Li on 24 May 2009. Paratypes: 3 females, same data as holotype except 25 May-5 June 2009.

Diagnosis. Postocellar line as long as ocular-ocellar line. Area petiolaris of propodeum high (Fig. 7) with strong median longitudinal carina and irregular oblique longitudinal wrinkles. First and second tergites (Fig. 8) with distinct subposterior transverse depressions. First tergite approximately $0.8 \times$ as long as posterior width. Head except clypeus, mesosoma, metasoma (Fig. 8), and hind leg (Fig. 1) black, except that basal 0.3 of hind tibia brownish and its spurs white.

Description. Body length $6.0-7.0 \mathrm{~mm}$. Fore wing length $6.0-6.5 \mathrm{~mm}$.

Head. Inner orbits parallel. Face (Fig. 2) approximately $1.9 \times$ as wide as long, slightly evenly convex, lateral portion shagreened, upper-median portion with distinct punctures; lower-median portion with indistinct punctures; upper margin with median small tubercle. Clypeus approximately $2.4 \times$ as wide as long, smooth, shiny, with sparse shallow indistinct punctures, apical median portion convex; median section of apical margin distinctly depressed. Basal portion of mandible with dense indistinct punctures; upper tooth sharper and slightly longer than lower tooth. Malar area and vertex (Fig. 4) shagreened. Malar space approximately $0.5 \times$ as long as basal width of mandible. Postocellar line approximately same length as ocular-ocellar line. Gena (Fig. 3) with fine punctures. Frons (Fig. 5) slightly convex medially, with dense fine punctures. Antenna with 31 flagellomeres; ratio of length from first to fifth flagellomeres approximately: 6.5:4.0:3.5:3.5:3.0. Occipital carina reaching hypostomal carina slightly above base of mandible.

Mesosoma. Along anterior margin of pronotum (Fig. 6) with dense fine punctures; lateral concavity with weak oblique transverse wrinkles; upper-posterior portion with dense fine punctures. Mesoscutum, scutellum and postscutellm with fine punctures. Notauli reaching beyond middle. Scutoscutellar groove almost shiny. Mesopleuron (Fig. 6) slightly shagreened, upper-median portion with fine transverse wrinkles; speculum shiny, smooth. Upper end of epicnemial carina approximately reaching to 0.6 distance to subtegular ridge. Metapleuron evenly convex, with dense punctures; lower posterior portion with oblique wrinkles. Ratio of length of hind tarsomeres from first to fifth approximately: 10.0:5.0:3.5:2.0:2.5. Wings hyaline. Fore wing with vein $1 \mathrm{cu}-\mathrm{a}$ slightly distal to M\&RS. Postnervulus intercepted at lower 0.4 . Hind wing vein 1-cu approximately $1.5 \times$ as long as cu-a. Propodeum (Fig. 7) with complete strong median longitudinal and posterior transverse carinae; median longitudinal carinae almost parallel; between median longitudinal carinae and area petiolaris shiny, remain areae with dense distinct punctures; area petiolaris with strong median longitudinal carina and irregular oblique longitudinal wrinkles. Propodeal spiracle small, circular, located at basal 0.25.

Metasoma. First three tergites (Fig. 8) with dense punctures. Subposterior portions of first and second tergites with weak transverse depressions. First tergite approximately $0.8 \times$ as long as posterior width, with irregular short wrinkles; dorsal median carina reaching to 0.6 length of first tergite; dorsolateral and ventrolateral carinae 
complete; postpetiole strongly convex; spiracle small, circular, convex, located approximately at anterior 0.4 of first tergite. Second and third tergites (Fig. 8) approximately $0.5 \times$ as long as posterior width. Fourth and subsequent tergites with relatively sparse fine punctures. Ovipositor sheath (Fig. 9) approximately $2.3 \times$ as long as its maximum width, from middle evenly narrowed posteriorly.

Colouration (Fig. 1). Black, except for following: clypeus, maxillary palpi, labial palpi, malar area, upper-posterior corners of pronotum, tegulae yellowish brown; mandible except base and teeth, fore and middle femora, tibiae and tarsi, apexes and bases of hind femora red brown; ventro-basal portions of hind tibiae brownish yellow; antennae, pterostigma and veins brownish black. Second and third metasomal sternites black brown.

Male. Unknown.

Distribution. China (Jilin).

Host. Pristiphora erichsonii (Hartig).

\section{Differential diagnosis}

The new species is similar to Rh. jussilai Reshchikov, 2016, but can easily be distinguished from it by the following combinations of characters: occipital carina reaching hypostomal carina slightly above base of mandible; area petiolaris of propodeum with strong median longitudinal carina; hind femur black. Rhinotorus jussilai: occipital carina reaching hypostomal carina distinctly above base of mandible; area petiolaris of propodeum without median longitudinal carina; hind femur brownish red.

\section{Discussion}

The new species is the only species of Rhinotorus recorded in the southeastern part of the Eastern Palearctic Region. The genus is not recorded in this part of Russia, in Korea and Japan. Nevertheless in the collections from the boreal and oriental part of China there are unidentified species of this genus. Rhinotorus need in further taxonomical research.

\section{Acknowledgements}

The authors are deeply grateful to Drs Gavin R. Broad (NHMUK) and Dmitry R. Kasparyan (ZISP) for their help in the study on the genus and reviewing the manuscript. This research was supported by the National Natural Science Foundation of China (NSFC, No. 31110103062, No. 31501887) and by key project of Sciencetechnology basic condition platform from The Ministry of Science and Technology of the People's Republic of China (Grant No. 2005DKA21402). 


\section{References}

Broad GR, Shaw MR, Fitton MG (2018) Ichneumonid Wasps (Hymenoptera: Ichneumonidae): their Classification and Biology. Royal Entomological Society and the Field Studies Council, Handbooks for the Identification of British Insects 7(12): 1-418.

Coppel HC, Leius K (1955) History of the larch sawfly, with notes on origin and biology. The Canadian Entomologist 87(3): 103-111. https://doi.org/10.4039/Ent87103-3

Drooz AT (1975) Mesoleius tenthredinis and other parasites of the larch sawfly in the Eastern United States. Environmental Entomology 4(4): 645-650. https://doi.org/10.1093/ee/4.4.645

Drooz AT, Thompson LC (1986) Collecting, rearing, shipping, and monitoring Olesicampe benefactor (Hymenoptera: Ichneumonidae), a parasite of the larch sawfly, Pristiphora erichsonii (Hymenoptera: Tenthredinidae). The Great Lakes Entomologist 19: 181-184.

Kulman HM, Thompson LC, Witter JA (1974) Introduction of parasites of the larch sawfly in Minnesota. The Great Lakes Entomologist 7(1): 23-25.

Li T, Sheng M-L, Sun S-P, Luo Y-Q (2014) Parasitoids of larch sawfly, Pristiphora erichsonii (Hartig) (Hymenoptera: Tenthredinidae) in Changbai Mountains. Journal of Natural History 48(3-4): 123-131. https://doi.org/10.1080/00222933.2013.791930

Meyer NF (1936) Parasitic Hymenoptera in the family Ichneumonidae of the USSR and adjacent countries. Part 5. Tryphoninae. Opredeliteli Faune SSSR 21(5): 1-340.

Muldrew JA (1967) Biology and initial dispersal of Olesicampe (Holocremnus) sp. nr. nematorum (Hymenoptera: Ichneumonidae), a parasite of the larch sawfly recently established in Manitoba. The Canadian Entomologist 99(3): 312-332. https://doi.org/10.4039/Ent99312-3

Pschorn-Walcher H, Zinnert KD (1971) Investigations on the ecology and natural control of the larch sawfly (Pristiphora erichsonii) (Hym.: Tenthredinidae) in central Europe. Part II. Natural enemies: their biology and ecology, and their role as mortality factors in P. erichsonii. Commonwealth Institute of Biological Control Technical Bulletin 14: 1-50.

Reshchikov AV (2016) A revision of the genus Rhinotorus Förster, 1869 (Hymenoptera, Ichneumonidae, Ctenopelmatinae), with descriptions of three new species and an illustrated identification key. European Journal of Taxonomy 235: 1-40. https://doi.org/10.5852/ ejt.2016.235

Richmond JA, Werner RA, Drooz AT (1975) Larch sawfly, Pristiphora erichsonii (Hymenoptera: Tenthredinidae) and its parasitoids from Alaska. Journal of the Entomological Society of British Columbia 92: 25-27.

Sheng M-L, Chen G-F (2001) Ichneumonidae parasitizing sawflies from China (Hymenoptera). Entomofauna 22: 413-420.

Taeger A, Liston AD, Prous M, Groll EK, Gehroldt T, Blank SM (2018) ECatSym - Electronic World Catalog of Symphyta (Insecta, Hymenoptera). Program version 5.0 (19 Dec 2018), data version 40 (23 Sep 2018). - Senckenberg Deutsches Entomologisches Institut (SDEI), Müncheberg. https://sdei.de/ecatsym/ [Access: 16 Apr 2020]

Townes HK, Momoi S, Townes M (1965) A Catalogue and Reclassification of the Eastern Palearctic Ichneumonidae. Memoirs of the American Entomological Institute 5: 1-661.

Townes HK (1970) The genera of Ichneumonidae, Part 3. Memoirs of the American Entomological Institute 13: 1-307. 
Wong HR (1974) The identification and origin of the strains of the larch sawfly, Pristiphora erichsonii (Hymenoptera: Tenthredinidae), in North America. The Canadian Entomologist 106(11): 1121-1131. https://doi.org/10.4039/Ent1061121-11

Xiao GR (1992) Forest insects of China ( $2^{\text {nd }}$ edn.). Beijing: China Forestry Publishing House, Beijing, $1362 \mathrm{pp}$.

Yang ZQ, Yao YX, Cao LM (2015) Chalcidoidea parasitizing forest defoliators (Hymenoptera). Science Press, Beijing, 283 pp.

Yu DS, van Achterberg C, Horstmann K (2016) Taxapad 2016, Ichneumonoidea 2015. Data base on flash-drive. Nepean, Ontario.

Zhou SZ, Huang XY, Zhang Z, Wang HB, Zhang PY (1995) A Study on the biology and ecology of the larch sawfly, Pristiphora erichsonii and its control. Forest Research 8: 145-151.

Zinnert KD (1969) Vergleichende Untersuchungen zur Morphologie und Biologie der Larvenparasiten (Hymenoptera Ichneumonidae und Braconidae) mitteleuropäischer Blattwespen aus der Subfamily Nematinae (Hymenoptera: Tenthredinidae) Teil I. Zeitschrift für Angewandte Entomologie 64: 180-217. https://doi.org/10.1111/j.1439-0418.1969.tb03036.x 